\title{
E-Shaped Microstrip Patch Antenna for Ku Band
}

\author{
Razin Ahmed and Md. Fokhrul Islam \\ Department of Electrical and Electronic Engineering \\ Islamic University of Technology \\ Board Bazar -1704, Gazipur, Bangladsh
}

\begin{abstract}
Technology has been developing day by day where satellite communication has become daily part of our life. As the technological devices are getting smaller demand for multiband operating antennas are growing faster to the consumers. This paper represents an E shaped Microstrip Patch Antenna for multiband operations in $\mathrm{Ku}$ band. The design has been made on low cost material of FR4 substrate having dielectric constant of 4.2 with thickness of $1.6 \mathrm{~mm}$. The proposed scheme and probe feeding technique provide designed antenna to operate in three different frequencies range in $\mathrm{Ku}$ band. The antenna resonates at $12.4 \mathrm{GHz}, 13.28$ $\mathrm{GHz}$, and $14.45 \mathrm{GHz}$ with directivity gain of 8.6, 9.5 and 7.4 respectively. Designing and simulation of this antenna has been done by IE3D software. In this paper different types of antenna characteristics have been studied.
\end{abstract}

\section{Keywords}

Rectangular Mircostrip Patch antenna (RMPA), Mircostrip Patch antenna (MPA), Radio frequency (RF)

\section{INTRODUCTION}

Rapid development in wireless communication system has been exaggerated since the birth of first radio communication system. There are many ranges of frequency band for different communication system in current time; they are allocated to services different purpose in modern life among them demand for satellite communication has been increased due to fast growth in high resolution mapping, satellite altimetry, radio astronomy service, space research service, mobile satellite service, radiolocation service (radar), and radio navigation. These applications and devices mainly operate in $\mathrm{Ku}$ band which is allocated in the microwave radio region of the electromagnetic spectrum. The antenna devices with single radiator that can transmit and receive multiple frequency bands become more efficient and desirable for commercial activities. Many researchers from universities and industries have introduced multiband antennas techniques passed years among them especially PIN diodes, switches and varactor diodes have been used. Main drawback of the design is they need to use a controlling turn ON/OFF switch for reconfigurable frequency operations [1, 2, \& 3]. There are other antennas which can also provide multiband such as Sierpinski fractal and printed inverted $\mathrm{F}$ antennas but they are highly intricacy in structure $[4,5, \& 6]$.

Micro-strip patch antennas have become popular in recent times. Compared with the conventional antenna, it has more multilateral advantages for planer profile, ability to operate in microwave frequency range, inexpensive to manufacture and especially easy to assemble in integrated circuit technology. The low profile planar configuration of Micro-strip antennas can be easily made conformal to host plane. Their light weight, low volume and low fabrication cost, allows them to be manufactured in large quantities.

In 1950s the abstract idea of Micro-strip antenna was first introduced by G. A. Deschamps. After the evolution of the printed circuit board (PCB) technology in the 1970s, Howell and Munson developed the first practical Micro-strip antenna, which opens extensive area of research all over the world [7]. The basic structure consists of a conducting patch of any nonplanar or planar geometry on one side of a dielectric substrate and a ground plane on other side. Ground plane provides enough reflections to the fringing fields due to the changes in length of patch antenna. Micro-strip patch antenna can be fed through different techniques among them probe feed and Micro-strip line feed are most popular and others are proximity coupled feed and aperture/slot-coupled feed.

The proposed antenna serves for fixed and broadcasting satellite in frequency range of (12.2 to 12.7) GHz; Earth exploration satellite, aeronautical radio navigation and space research from (13.24 to 13.4$) \mathrm{GHz}$; fixed mobile, fixed satellite (earth-to-space) and mobile satellite (earth-to-space) from (14.4 to 14.5$) \mathrm{GHz}$ [ $9 \& 10$ ].

\section{ANTENNA DESIGNS}

To design desirable $\mathrm{E}$ shaped MPA, first rectangular microstrip patch antenna has been constructed based on the standard designing procedure. The length and width of the antenna dimensions are determined by following equation [8].

$$
\begin{aligned}
& W=\frac{v_{o}}{2 f} \sqrt{\frac{2}{\varepsilon_{r}+1}} \\
& \varepsilon_{\text {eff }}=\frac{\varepsilon_{r}+1}{2}+\frac{\varepsilon_{r}-1}{2}\left[1+12 \frac{h}{W}\right]^{\frac{-1}{2}} \\
& \Delta L=0.421 h \frac{\left(\varepsilon_{\text {eff }}+0.3\right)\left(\frac{W}{h}+0.264\right)}{\left(\varepsilon_{\text {eff }}-0.258\right)\left(\frac{W}{h}+0.8\right)} \\
& L=\frac{1}{2 f_{r} \sqrt{\varepsilon_{\text {eff }}} \sqrt{\mu_{o} \varepsilon_{o}}}-2 \Delta L
\end{aligned}
$$

Here $W$ is the width of the patch, $v_{o}$ is the speed of light in a vacuum, $\varepsilon_{r}$ is the dielectric constant of the substrate, $f_{r}$ is the target frequency, $\varepsilon_{\text {eff }}$ is the effective dielectric constant of the material, $\Delta L$ represents the extension in length caused by the fringing effect, $\mathrm{h}$ is the thickness of the substrate and $\mathrm{L}$ is the length of the patch. 
The calculated parameters are transferred to the software for simulation. RMPA has patch and ground plane dimensions of (WxL) $24 \mathrm{~mm} \times 17 \mathrm{~mm}$ and $\left(\mathrm{W}_{\mathrm{g}} \mathrm{xL}\right) 34 \mathrm{~mm} \times 27 \mathrm{~mm}$ respectively. It has been designed on FR4 substrate with dielectric constant of 4.2 and thickness of $1.6 \mathrm{~mm}$ from the ground plane. The RMPA is excited with probe feeding technique at position of $\left(\mathrm{x}_{0}, \mathrm{y}_{0}\right)=(15.6,19.6)$

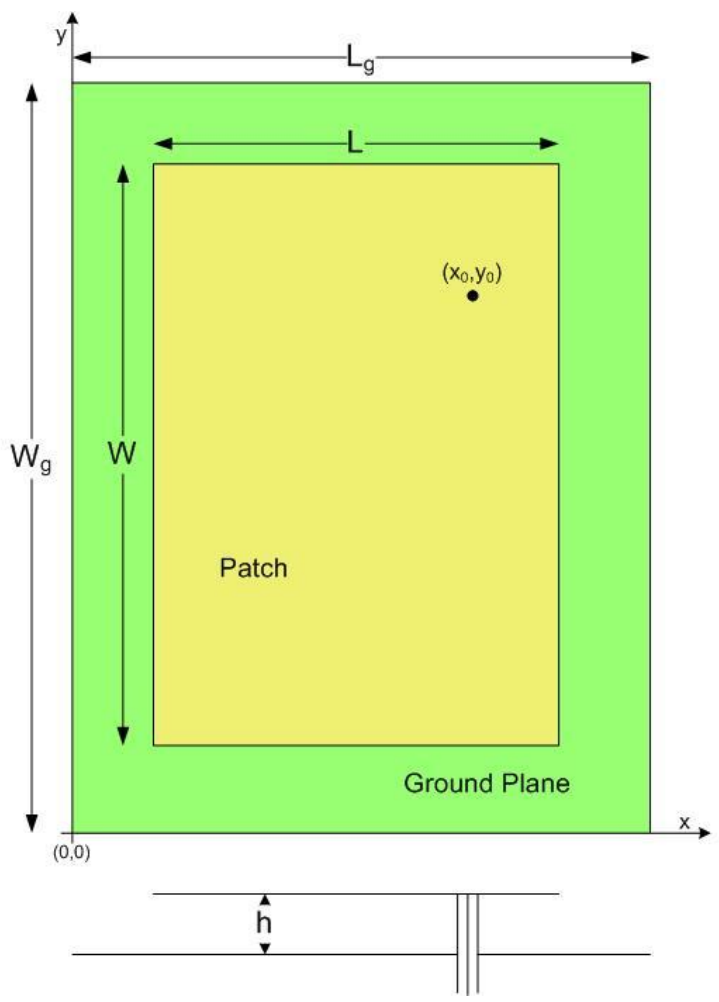

Fig 1: Basic structure of RMPA

Figure 2 represent $\mathrm{E}$ shaped MPA with same dimensions of RMPA where two parallel slots are cutoff from rectangular patch to perturb the surface current patch and introducing local inductive effect which is responsible for multiband purpose $[11 \& 12]$. The dimensions are given by $l_{1}=7 \mathrm{~mm}, 1_{2}$ $=10 \mathrm{~mm}, \mathrm{w}_{1}=6 \mathrm{~mm}, \mathrm{w}_{2}=3 \mathrm{~mm}$ shown in Table 1

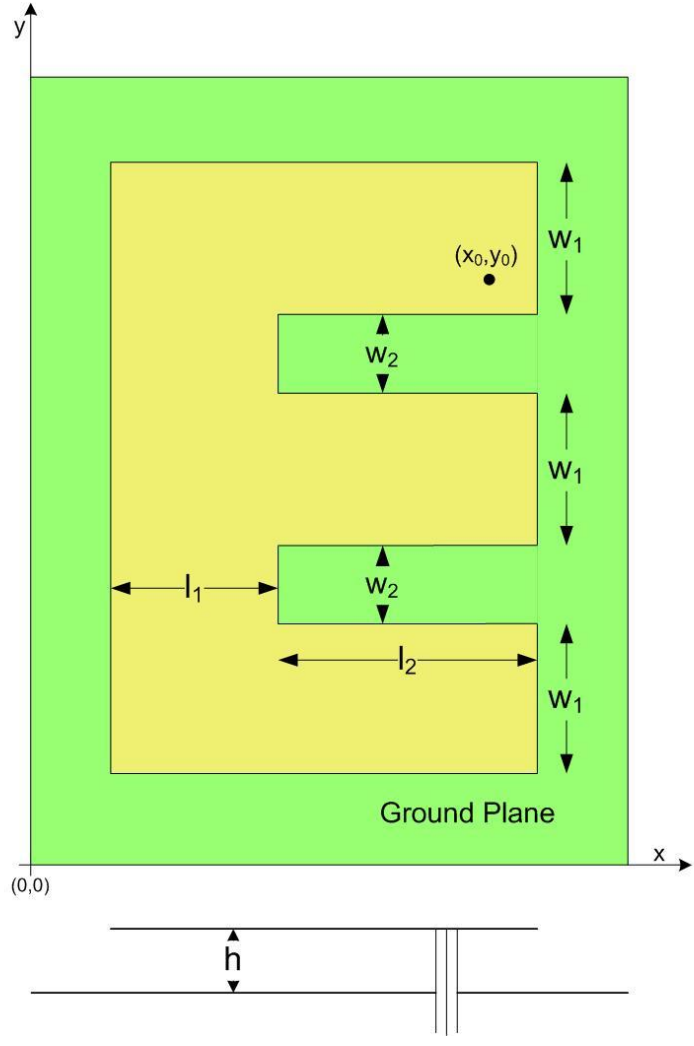

Fig 2: Geometry of proposed antenna

Table 1. Full Dimensions for proposed antenna

\begin{tabular}{|c|c|}
\hline Parameters & Dimension (mm) \\
\hline $1_{1}$ & 7 \\
\hline $1_{2}$ & 10 \\
\hline $\mathrm{w}_{1}$ & 6 \\
\hline $\mathrm{w}_{2}$ & 3 \\
\hline $\mathrm{L}_{\mathrm{g}}$ & 27 \\
\hline $\mathrm{W}_{\mathrm{g}}$ & 34 \\
\hline $\mathrm{L}$ & 17 \\
\hline $\mathrm{W}$ & 24 \\
\hline
\end{tabular}

\section{RESULT AND SIMULATION}

The performance of the proposed antenna is analyzed by using commercially available IE3D software which has Fast EM Design Kit for real-time full-wave EM tuning, optimization and synthesis and help to get precise result for mutiband. From the Figure 3 it is observed that RMPA operates at resonant frequencies of $12.73 \mathrm{GHz}$ and $14.66 \mathrm{GHz}$ with return loss of $-16.5 \mathrm{~dB}$ and $-7.7 \mathrm{~dB}$ respectively. The bandwidth of resonant frequencies is noticed after $-10 \mathrm{~dB}$ critically where the bandwidth of first operating frequency is $170 \mathrm{MHz}$ but bandwidth of other operating frequency is 0 because it does not have minimum return loss. RMPA operates with only $2.83 \%$ of $\mathrm{Ku}$ band coverage. 


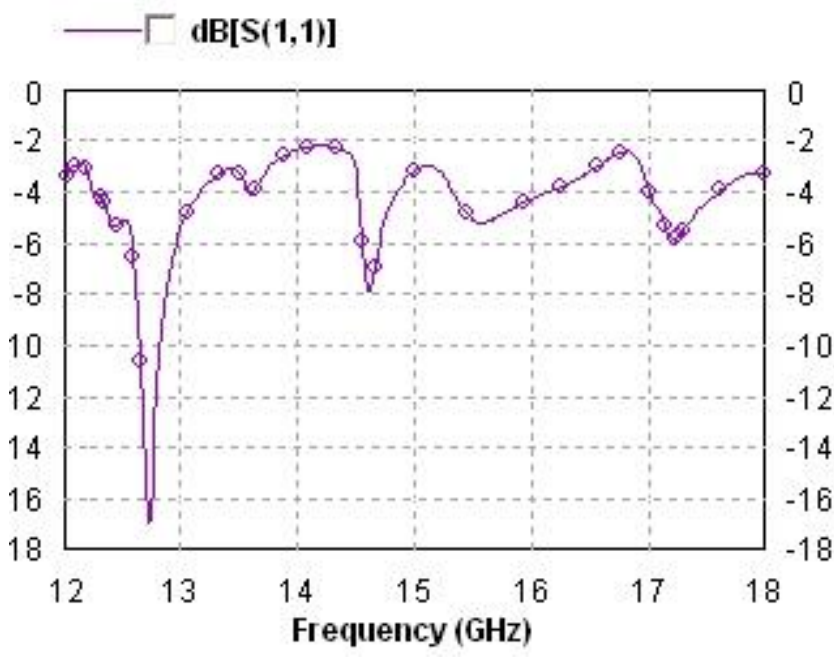

Fig 3: Reflection coefficient $\left(S_{11}\right)$ of RMPA

Figure 4 depicts the result of the return loss of the proposed patch antenna. It is observed that resonant frequencies appeared in range of (12-18) $\mathrm{GHz}$ which are $12.4 \mathrm{GHz}, 13.28$ $\mathrm{GHz}$ and $14.45 \mathrm{GHz}$ under $\mathrm{K}_{\mathrm{u}}$ with return loss of $-16 \mathrm{~dB}$, $27.7 \mathrm{~dB}$ and $-11.6 \mathrm{~dB}$ respectively. The bandwidths of resonant frequencies are typically about $235 \mathrm{MHz}, 375 \mathrm{MHz}$, and $200 \mathrm{MHz}$ respectively. The sum of bandwidths is 792 $\mathrm{MHz}$ which covers total $13.20 \%$ of Ku band.

\section{$-\Gamma \mathrm{dB}[\mathrm{S}(1,1)]$}

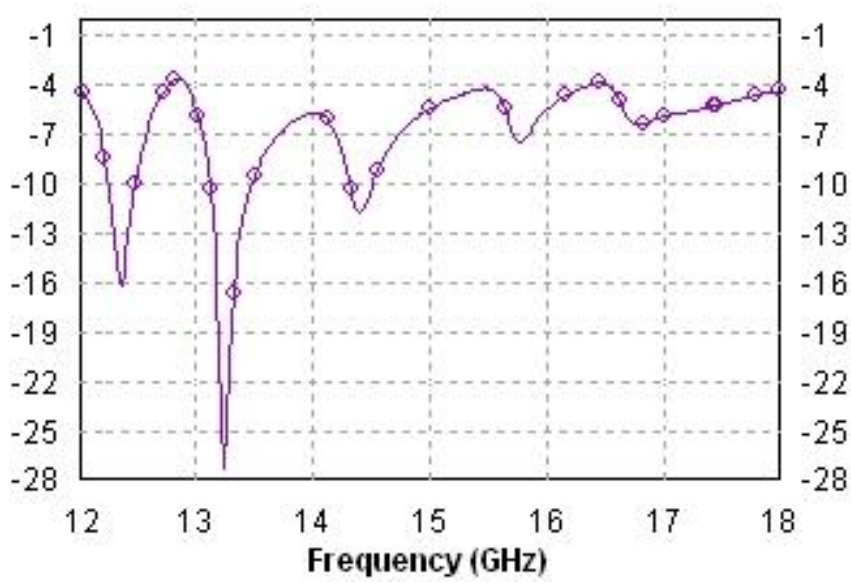

Fig 4: Reflection coefficient $\left(S_{11}\right)$ of $E$ shaped MPA

Figure 5 shows the comparison between RMPA and proposed E shaped s MPA. It is cleared that proposed antenna shows better performance in antenna characteristic. Figure 6 represents VSWR of E shaped MPA where it has been observed that the ratio of the maximum voltage of a standing wave pattern on a transmission line to the minimum voltage on the line is less than 2 at operating frequencies.

\section{$-Г$ E shaped MPA $\mathrm{dB}[\mathrm{S}(1,1)]$ RMPA dB[S(1,1)]}

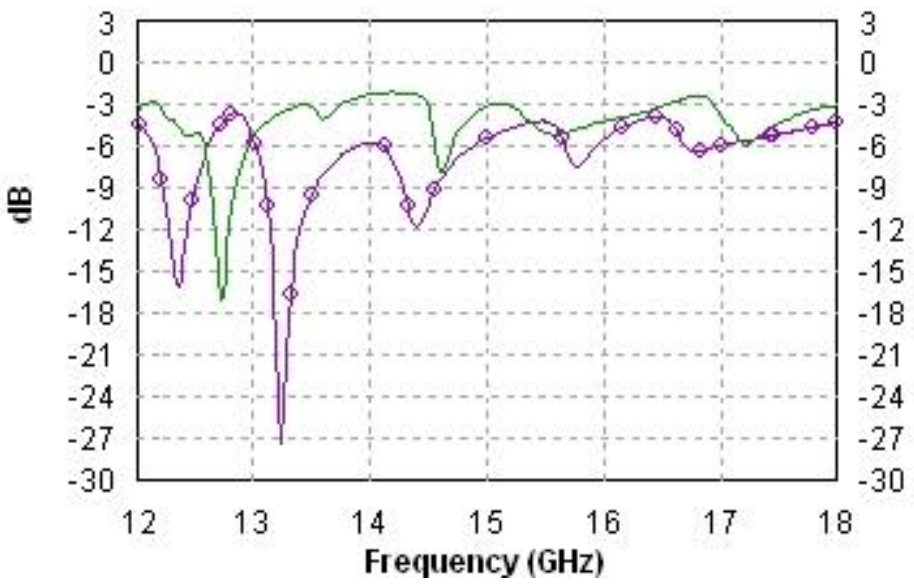

Fig 5: Reflection coefficient $\left(S_{11}\right)$ of $E$ shaped MPA and RMPA

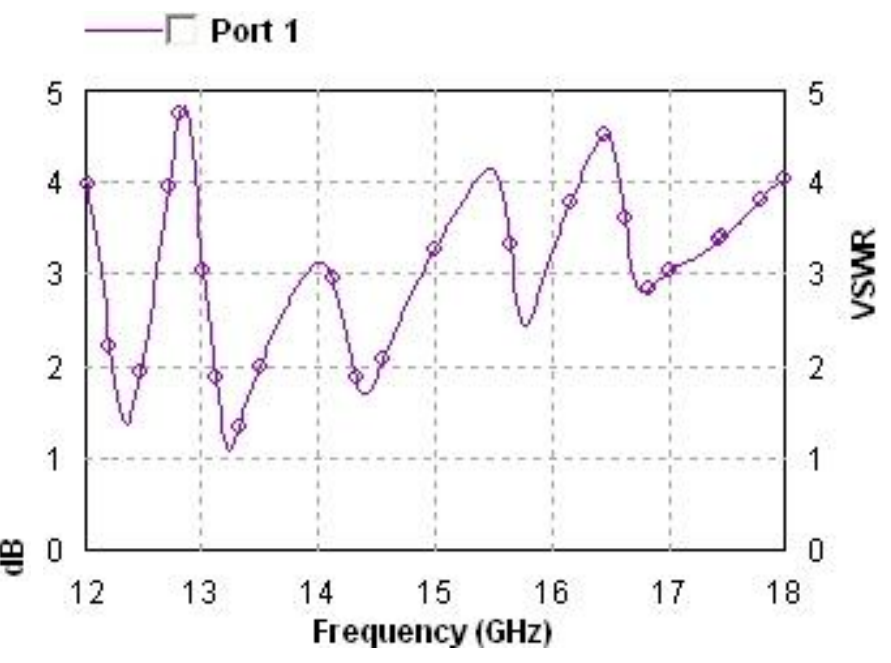

Fig 6: VSWR of proposed antenna

Figure $7,8,9,10,11 \& 12$ shows radiation pattern of proposed antenna where the gain and directivity gain are 4.7 $\mathrm{dBi}, 3.04 \mathrm{dBi}$ and $0.94 \mathrm{dBi}$ and $8.6 \mathrm{dBi}, 9.5 \mathrm{dBi}$, and $7.4 \mathrm{dBi}$ respectively. Table 2 illustrates the comparison study in terms of antenna characteristics of RMPA and E shaped MPA where proposed antenna is more efficient and have multiband frequencies in $\mathrm{Ku}$ band. 


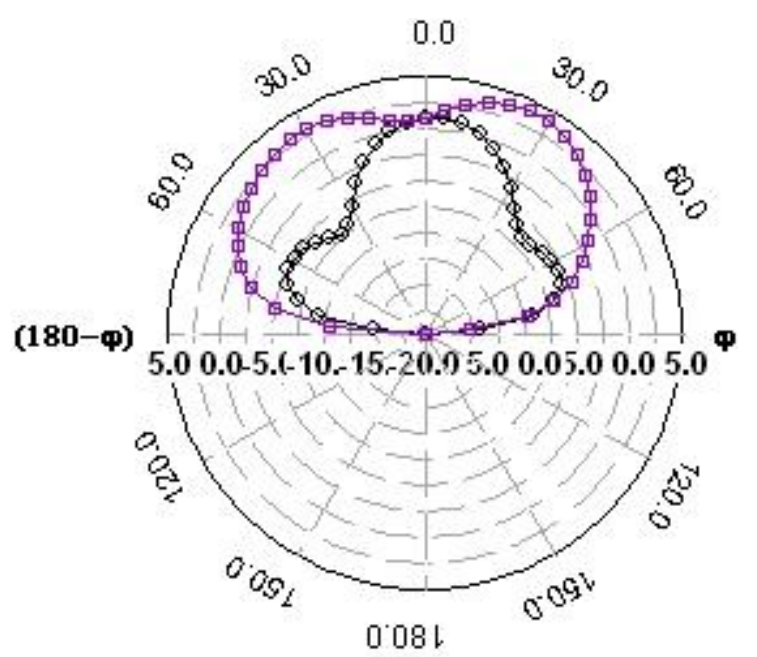

Elevation Pattern Gain Display

(dBi)

Fig 7: Antenna Gain at $12.4 \mathrm{GHz}$

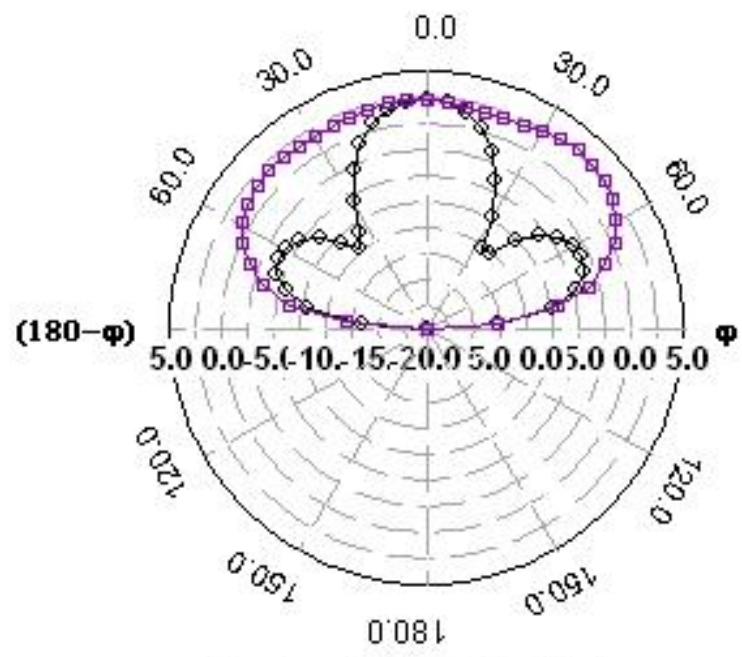

Elevation Pattern Gain Display (dBi)

Fig 8: Antenna Gain at $13.28 \mathrm{GHz}$

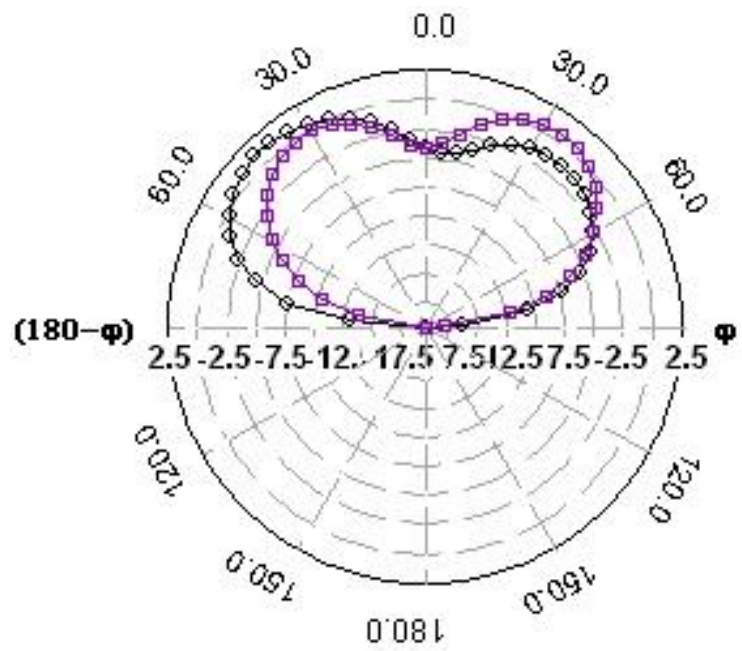

Elevation Pattern Gain Display (dBi)

Fig 9: Antenna Gain at $14.45 \mathrm{GHz}$

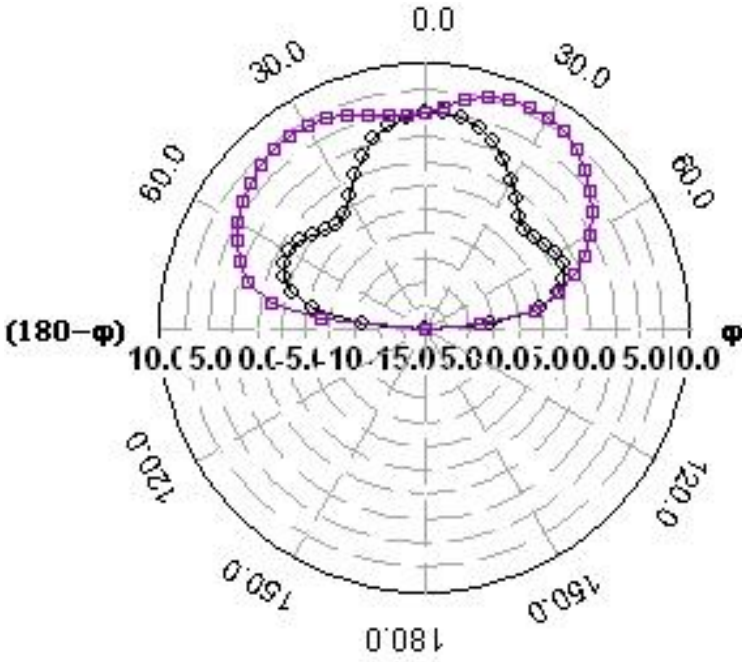

Elevation Pattern Directivity Display (dBi)

Fig 10: Directivity at 12.4 GHz of proposed antenna

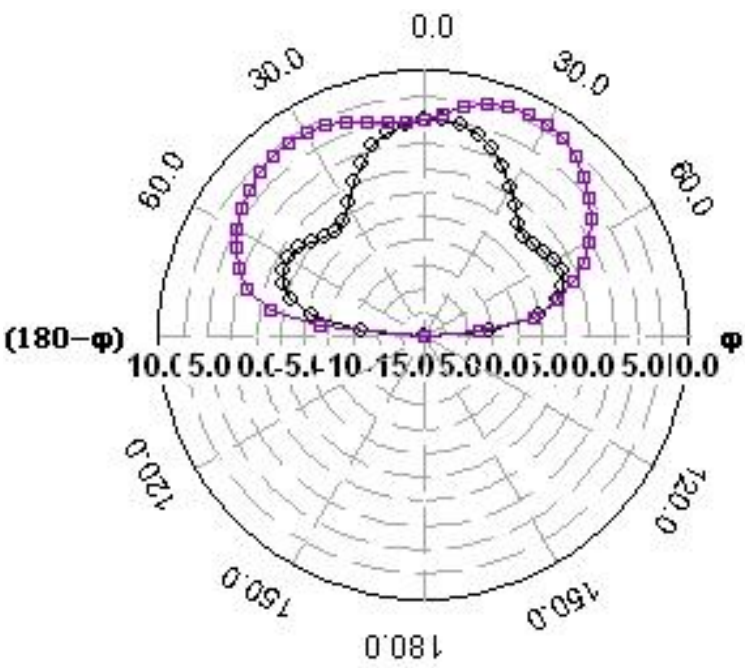

Elevation Pattern Directivity Display (dBi)

Fig 11: Directivity at 13.28 GHz of proposed antenna

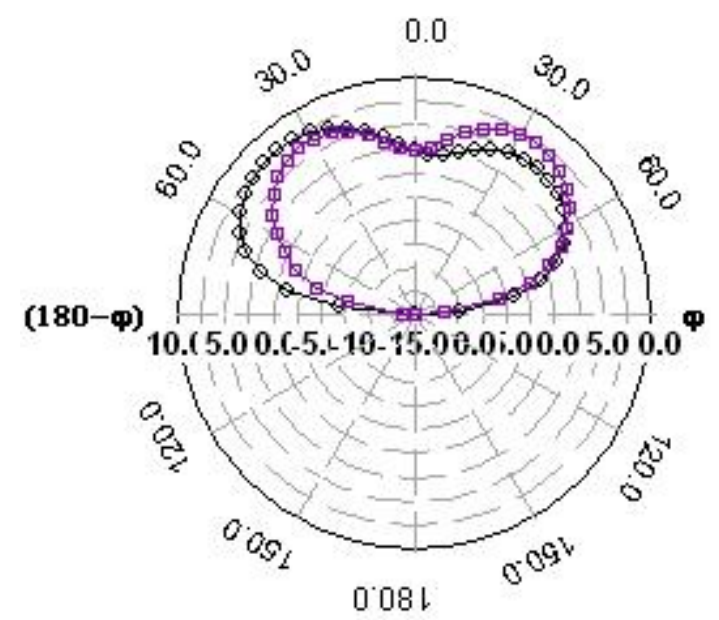

Elevation Pattern Directivity Display (dBi)

Fig 12: Directivity at $14.45 \mathrm{GHz}$ of proposed antenna 
Table 2. RMPA vs E shaped MPA

\begin{tabular}{|c|c|c|c|c|}
\hline Antenna Parameters & RMPA & \multicolumn{3}{|c|}{ E shaped MPA } \\
\hline $\begin{array}{c}\text { Resonant Frequencies } \\
(\mathrm{GHz})\end{array}$ & 12.73 & 12.4 & 13.28 & 14.45 \\
\hline Return loss (dB) & -16.5 & -16 & -27.7 & -11.6 \\
\hline Bandwidth (MHz) & 170 & 235 & 357 & 200 \\
\hline Gain (dBi) & 4.2 & 4.7 & 3.04 & .09 \\
\hline Directivity (dBi) & 8.5 & 8.6 & 9.5 & 7.4 \\
\hline
\end{tabular}

\section{CONCLUSION}

A compact $\mathrm{E}$ shaped MPA has been presented in this paper for multiband operation in $\mathrm{Ku}$ band range. The proposed antenna can be used for fixed and broadcasting satellite, earth exploration satellite, aeronautical radio navigation, space research, fixed mobile, fixed satellite (earth-to-space) and mobile satellite (earth-to-space) applications. In this paper it has been observed that trimming down two parallel slots (E shape) helps to achieve multiband and have improved antenna characteristics respected to RMPA. The resonant frequencies occurred at $12.4 \mathrm{GHz}, 13.28 \mathrm{GHz}$, and $14.45 \mathrm{GHz}$ with satisfactory bandwidths and gains. The proposed antenna has maximum gain and directivity of $4.9 \mathrm{dBi}$ and $10.5 \mathrm{dBi}$ respectively. For further enhancements in antenna performance, new artificial man made Metamaterial can be introduced. Recently it has drawn attention to many RF engineers and researchers.

\section{REFERENCES}

[1] D. Peroulis, K. Sarabandi and L. B. P. Katehi. 2005. Design of reconfigurable slot antennas. IEEE Trans. Antennas Propag., vol. 53, no.7, pp. 645-654.

[2] H. Okabe and K. Takei. 2001. Tunable antenna system for $1.9 \mathrm{GHz}$ PCS handsets. IEEE Antennas Propag. Int. Symp., vol. 1, pp. 166- 169.
[3] F. Yang and Y. R. Samii. 2002. A reconfigurable patch antenna using switchable slots for circular polarization diversity. IEEE Micro. Wireless Comp. Lett., vol. 12, no. 3, pp. 96-98.

[4] C.T.P. Song, P.S. Hall, and H.G. Shiraz. May 2003. Perturbed: Sierpinski Multiband Fractal Antenna with Improved Feeding Technique. IEEE Trans. Antennas Propag., vol. 51, no. 5, pp. 1011-1017.

[5] D.M. Nashaat, H.A. Elsadek, and H. Ghali. Aug. 2005. Single Feed Compact Quad-Band PIFA Antenna for Wireless Communication Applications. IEEE Trans. Antennas Propag., vol. 53, no. 8, pp. 2631- 2635.

[6] Paitoon Rakluea, Noppin Anantrasirichai, Kanok Janchitrapongvej, and Toshio Wakabayashi. June 2009. Multiband Microstrip-Fed Right Angle Slot Antenna Design for Wireless Communication Systems. ETRI Journal, Volume 31, Number 3.

[7] Howell, J.Q. 1972. Microstrip Antennas, presented in International symposium on Antennas and Propagation Soc., Williamburg.

[8] Garg, R., R. Bhartia, P. Ittipiboon, A. and I. Bahl,. 1980. Microstrip Antenna Design Handbook. Artech House, Boston, London.

[9] David Lewin, Phillipa Marks and Stefano Nicoletti. 2013. Valuing the use of spectrum in the EU. London, EC4A 3BF, United Kingdom.

[10] Final Report Prepared for Ofcom. 2011. Frequency Band Review for Fixed Wireless Service. Ægis Systems Limited, 2315/FLBR/FRP/3.

[11] B.K Ang and B.K Chung. 2007. A Wideband E-shaped Microstrip patch antenna for 5-6 GHz wireless communications. Progress In Electromagnetics Research, PIER 75, pp. 397-407.

[12] F. Yang, X. Zhang, X. Ye, and Y. Rahamt-Samii. 2001. Wide band E-shaped patch antenna for wireless communications," IEEE Trans. Antennas Propag., vol. 49, no. 7, pp. 1094-1100. 